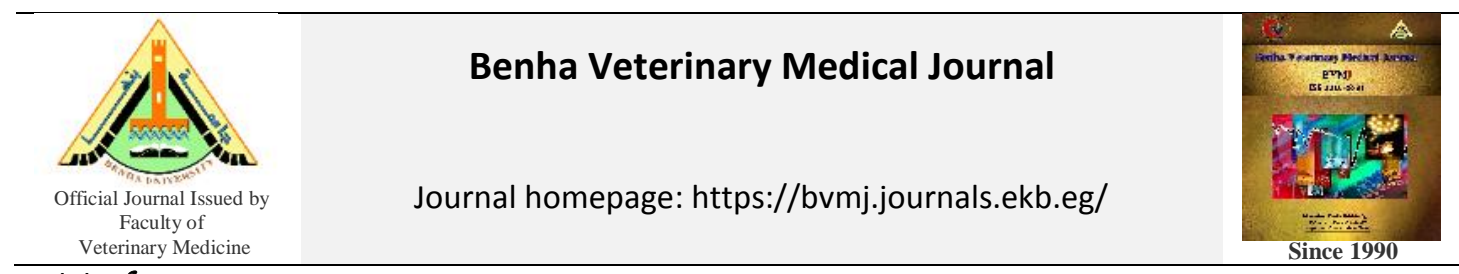

Original Paper

\title{
Comparative immunopathological study of various intra-cloacal infectious bursal disease vaccine doses
}

Abaza M. A. ${ }^{*}$, Elboraay E. M. ${ }^{1}$, Saad A. E., Zayan K. A.

Avian and Rabbit Diseases Department, Faculty of Veterinary Medicine, Benha University, Egypt

\begin{tabular}{|c|c|}
\hline ARTICLE INFO & ABSTRACT \\
\hline $\begin{array}{l}\text { Keywords } \\
\text { IBD vaccine dose } \\
\text { Immunopathology } \\
\text { Infectious bursal disease } \\
\text { Intra-cloacal vaccination } \\
\text { route } \\
\text { Received } 12 / 10 / 2020 \\
\text { Accepted 29/10/2020 } \\
\text { Available On-Line } \\
\text { 20/01/2021 }\end{array}$ & $\begin{array}{l}\text { Infectious bursal disease (IBD) is a contagious immunosuppressive viral infection of young } \\
\text { chickens. Intra-cloacal approach is effective for vaccinating chicks with high maternally } \\
\text { derived IBD antibodies; however, the vaccinal traditional dose may be unsuitable for this route. } \\
\text { A total of } 60 \text { one-day-old specific-pathogen-free (SPF) chicks were randomly distributed into } \\
\text { four groups. Group-1: was control and chicks in group-2: were vaccinated with } 10^{3.5} \text { TCID50 } \\
\text { of D78 strain/ bird via intra-cloacal route, chicks in group-3: were vaccinated with a ten-fold } \\
\text { higher dose ( } 10^{4.5} \text { TCID50/bird) and chicks in group- } 4 \text { : were vaccinated with a dose of } 10^{2.5} \\
\text { TCID50 of D78 strain/bird using same approach. IBD antibody titers were measured at the } 14^{\text {th }} \\
\text { and } 21^{\text {st }} \text { days of age. The immunosuppressive effects of different doses were determined } \\
\text { through humoral immune response to avian influenza and Newcastle disease vaccines, the } \\
\text { relative weight of primary lymphoid organs, and histopathologically evaluated bursal lesions. } \\
\text { The results indicated that a dose even ten-fold higher than the usual dose to SPF chicks via } \\
\text { intra-cloacal route caused neither morbidity nor mortality. All vaccine doses induced potent } \\
\text { immune responses against IBD, but the highest IBD antibodies titers were observed in group- } \\
4 \text { while IBD antibodies titers were decreased with increasing vaccine doses in other } \\
\text { experimental groups. Even the vaccinated birds showed moderate histopathological lesions and } \\
\text { the diminutive relative weight of bursae; there was no immunosuppressive effect in the immune } \\
\text { response to other vaccines in group- } 4 \text { and transient immunosuppressive effect in groups- } 2 \text { and- } \\
3 \text {. All that proves the safety and effectiveness of various intra-cloacal vaccination approach } \\
\text { doses. }\end{array}$ \\
\hline
\end{tabular}

\section{INTRODUCTION}

Infectious bursal disease (IBD) is a contagious immunosuppressive disease affecting young chicks. It is caused by a double-stranded RNA infectious bursal disease virus, which belongs to the genus Avibirnavirus of the family Birnaviridae (Teshome et al., 2015). Prevention of IBD in young chicks depends mainly on active immunization with IBD live vaccines while the traditional routes of live vaccine application may result in vaccination failure due to vaccine neutralization by maternally derived antibodies (Eterradossi and Saif, 2019). Anatomically, the bursa of Fabricius is sac-like pouch derived from the dorsal aspect of the proctodeum which linked with the cloaca through a slot-like duct (Oláh et al., 2013).

Cloacal drinking is a reflex stimulated by dripping the fluid onto the cloacal lips. That reflex subsequently leads to absorption of the fluids on the cloacal lips into the bursa of Fabricius (Sorvari et al., 1977; van der Sluis et al., 2009). Several studies were performed to assess the bursa antigenic absorption through cloacal drinking and its ability to induce an immune response (Sorvari et al., 1977; Schlink and Olson, 1987; de Azevedo and Betti, 1993; Uenaka et al., 1998). Abaza, et al., (2020) had been conduct a study to overcome the problem of vaccine neutralization by maternally derived antibodies through direct deliver the vaccinal strains to the bursa of Fabricius via the bursal duct with no effects on maternally-derived antibodies in the blood. The results of this study revealed that the novel intracloacal vaccination approach initiates a robust immune response against IBD at any age regardless of the level of maternally derived antibodies. Vaccinated chicks by the intra-cloacal vaccination route showed high protection against IBDV without immunosuppression effect or pathological changes in the bursa of Fabricius, in spite of early multiplication of the vaccine in bursal tissue. This vaccination approach gives optimistic results to overcome the problem of vaccine neutralization by maternally-derived antibodies and resolve the problem of the immunity gap (Abaza et al., 2020).

It is well known that during regular vaccination routes, the vaccine strains multiply in the intestine then make primary viremia to reach parenchymatous organs where the virus multiplies again. After that, a secondary viremia is initiated; thereby, the virus reaches the bursa of Fabricius. In addition to the titer of the vaccine strain which reach to bursa of Fabricius is not the titer of vaccinal dose. It may be amplified from multiplication in parenchymatous organs or diminished in long pathway from digestive system to bursa of Fabricius (Eterradossi and Saif, 2019). Thus, theoretically, it is expected that the ordinary IBD vaccine doses may not be suitable for the intra-cloacal vaccination approach. Simultaneously, reducing the vaccinal dose is associated with a significant decrease in the immune response (Belyakov \& Ahlers, 2009; Hessell et al., 2009) as well as the overdose of the vaccine results in atrophy and fibrosis of

*Corresponding author: Mohamed.abaza@fvtm.bu.edu.eg 
the bursae in one-day-old SPF chicks (Savic et al., 2004). Therefore, the current study aimed to compare the immunopathological responses of different intra-cloacal IBD vaccine doses in young chickens.

\section{MATERIAL AND METHODS}

\section{Ethics statement}

The experimental protocol was approved by the Institutional Animals Care and Use Committee, Research Ethics Board, Faculty of Veterinary Medicine, Benha University, Egypt, under the file number BUFVTM 05012019 for following animal welfare guidelines.

\subsection{Vaccines}

The used vaccines included 1) a commercially live IBD vaccine based on the D78 strain (10 $0^{3.5}$ TCID50 dose/bird) (Volvac IBD MLV®), 2) a live Newcastle disease (ND) vaccine applied according to the guidelines of the manufacturers and based on Hitchiner B1, and 3) an inactivated bivalent avian influenza (AI) $\mathrm{H} 5 \mathrm{~N} 1$ and $\mathrm{ND}$ vaccine (ME FLUVAC H5+ND-17®).

\subsection{Birds}

A total of 60 one-day-old SPF chicks (White Leghorn egglaying breed) were obtained from Koum Osheim ElFayoum, Egypt, and housed in isolation units of comparable size and management on litter. Feed and water were provided to the chicks ad libitum.

\subsection{Experimental design}

A total of 60 one-day-old SPF chicks were equally distributed into four groups (15 chicks/group). Group 1 nonvaccinated chicks (negative control group), while groups 2,3 and 4 were vaccinated against IBD on the first day of age via the intra-cloacal route. Group 2 chicks were vaccinated with the ordinary dose ( $10^{3.5}$ TCID50/bird). Meanwhile, Group 3 chicks were vaccinated with a dose ten-fold higher than that of the ordinary dose $\left(10^{4.5}\right.$ TCID50/bird $)$ to assess the immunopathological effect of a higher viral load and determine the safety of the vaccine when used via the intracloacal route according to (World Organization for Animal Health (OIE), 2012). Finally, to assess the effect of minimizing the direct viral load on the bursa, Group 4 chicks were vaccinated with a ten-fold lower dose than that the ordinary dose $\left(10^{2.5}\right.$ TCID50/bird). All birds were vaccinated on the $5^{\text {th }}$ day of age with the ND live vaccine via eye-drop route; later, at the $10^{\text {th }}$ day of age, they were subjected to subcutaneous vaccination with the inactivated bivalent AI H5N1 and ND vaccine. Morbidity and mortality rates were recorded along with the bird's life. To identify potential differences in the immune response to the different IBD vaccine doses, IBD antibody titers were measured using ELISA in five serum samples from each group collected at the $14^{\text {th }}$ and $21^{\text {st }}$ days of age. To evaluate the immune suppression effect of different vaccine doses, the humoral immune response to other vaccines (ND and $\mathrm{AI}$ ) was measured using $\mathrm{HI}$ in five serum samples from each group at the $21^{\text {st }}$ days of age. The relative weight of the primary lymphoid organs was estimated by euthanizing five chicks/group at the $7^{\text {th }}, 14^{\text {th }}$, and $21^{\text {st }}$ days of age, according to Tanimura et al., (1995). Finally, the bursae were collected from euthanized birds and fixed in $10 \%$ buffered formalin solution for further histopathological examination.

\subsection{Serology}

Blood for serology tests was collected from chicks in tubes at specific time according to experimental design then allowed to clot. The serum was aliquoted into Eppendorf tubes and stored at $-20^{\circ} \mathrm{C}$ until laboratory processing. Evaluation of antibody titers to IBDV was performed using ELISA (BioChek IBD Kit [CK113 IBD, Gouda, Netherlands]) following the manufacturer's instructions. Hemagglutination inhibition (HI) tests for ND and AI were conducted using a $1 \%$ washed chicken red blood cell suspension and $4 \mathrm{HA}$ units for $\mathrm{ND}$ and $\mathrm{AI}$ antigens, following standard procedures (OIE, 2012). HI results were recorded as reciprocal values of the highest dilution that showed complete button shape.

\subsection{Pathology}

Fixed bursae were routinely processed, and $4 \mu \mathrm{m}$-thick tissue paraffin sections were prepared and stained with hematoxylin and eosin stains (Banchroft, et al., 1996). The severity of bursal lesions was determined by comparing the mean scores of depletion and necrosis calculated according to the study by Sharma et al., (1989).

\subsection{Statistical analyses}

Statistical analyses were performed utilizing SPSS software (version 25.0; SPSS Inc., Chicago, IL, USA). Differences in IBD antibodies titers across the groups, the relative weight of immune organs, and the severity of bursal lesions were analyzed using the Two-Way Repeated Measured ANOVA and Tukey's multiple comparison tests. Differences among the groups in terms of the humeral immune response to ND and AI were analyzed via One-Way ANOVA and Duncan's post hoc tests. Probability $(\mathrm{P})$ values $<0.05$ were considered to indicate statistical significance

\section{RESULTS}

Throughout the experiment, neither morbidity nor mortality was recorded in all groups. The IBD vaccine administered via the intra-cloacal route at different doses induced a potent IBD immune response. However, differences in vaccine doses were associated with significant differences in IBDinduced immune responses, as titers significantly decreased with increasing vaccine doses. Group 4 chicks exhibited the highest IBD virus antibody titers (Table 1). Moreover, all vaccinated birds showed a significant reduction in the relative weight of the bursa in comparison with nonvaccinated birds. While there were only non-significant differences in the relative weight of the bursa and other immune organs between the vaccinated groups with different doses (Table 2).

Concerning the histopathological examination of the bursae, the lesions varied among vaccinated and non-vaccinated birds. Moreover, the vaccine dose had a significant effect on bursal lesions.

Table 1 infectious bursal disease virus antibody titers after intra-cloacal vaccination as measured by ELISA over time according to the experimental group (mean $\pm \mathrm{SD})$

\begin{tabular}{llll}
\multicolumn{2}{l}{ group $($ mean \pm SD). } & & \\
\cline { 1 - 4 } Groups & Dose $\left(\mathrm{TCID}_{50} /\right.$ bird $)$ & $14^{\text {th }}$ day PV & $21^{\text {st }}$ day PV \\
\hline 1 & none & $0.0 \pm 0.0^{\mathrm{A}}$ & $0.0 \pm 0.0^{\mathrm{C}}$ \\
2 & $10^{3.5}$ & $5022 \pm 280^{\mathrm{B}}$ & $7692 \pm 653^{\mathrm{B}}$ \\
3 & $10^{4.5}$ & $5570 \pm 1317^{\mathrm{B}}$ & $6738 \pm 435^{\mathrm{B}}$ \\
4 & $10^{2.5}$ & $6327 \pm 774^{\mathrm{A}}$ & $8284 \pm 689^{\mathrm{A}}$ \\
\hline
\end{tabular}

Values reflect the average for three birds. Values within a column followed by the same superscript letter are not significantly different $(P<0.05)$ 
Table 2 Relative weight of immune organs over time, according to the experimental group (mean \pm SD).

\begin{tabular}{|c|c|c|c|c|c|c|c|c|c|c|}
\hline \multirow[t]{2}{*}{ Group } & \multirow[t]{2}{*}{ Dose } & \multicolumn{3}{|c|}{ Bursa of Fabricius } & \multicolumn{3}{|c|}{ Thymus } & \multicolumn{3}{|c|}{ Spleen } \\
\hline & & $7^{\text {th }}$ day & 14th day & $21^{\text {st }}$ day & $7^{\text {th }}$ day & 14th day & $21^{\text {st }}$ day & $7^{\text {th }}$ day & 14th day & $21^{\text {st }}$ day \\
\hline 1 & none & $0.31 \pm 0.06^{\mathrm{A}}$ & $0.49 \pm 0.06^{\mathrm{A}}$ & $0.59 \pm 0.01^{\mathrm{A}}$ & $0.48 \pm 0.06^{\mathrm{A}}$ & $0.76 \pm 0.07^{\mathrm{A}}$ & $0.6 \pm 0.08^{\mathrm{A}}$ & $0.11 \pm 0.02^{\mathrm{A}}$ & $.18 \pm 0.03^{\mathrm{A}}$ & $0.20 \pm 0.02^{\mathrm{A}}$ \\
\hline 2 & $10^{3.5}$ & $0.15 \pm 0.04^{\mathrm{B}}$ & $0.19 \pm 0.04^{\mathrm{B}}$ & $0.23 \pm 0.04^{\mathrm{B}}$ & $0.45 \pm 0.08^{\mathrm{A}}$ & $0.62 \pm 0.1^{\mathrm{A}}$ & $0.71 \pm 0.16^{\mathrm{A}}$ & $0.11 \pm 0.019^{\mathrm{A}}$ & $0.17 \pm 0.02^{\mathrm{A}}$ & $0.22 \pm 0.03^{\mathrm{A}}$ \\
\hline 3 & $10^{4.5}$ & $0.17 \pm 0.05^{\mathrm{B}}$ & $0.15 \pm 0.03^{\mathrm{B}}$ & $0.19 \pm 0.05^{\mathrm{B}}$ & $0.35 \pm 0.03^{\mathrm{A}}$ & $0.69 \pm 0.13^{\mathrm{A}}$ & $0.7 \pm 0.17^{\mathrm{A}}$ & $0.12 \pm 0.01^{\mathrm{A}}$ & $0.18 \pm 0.03^{\mathrm{A}}$ & $0.18 \pm 0.03^{\mathrm{A}}$ \\
\hline 4 & $10^{2.5}$ & $0.14 \pm 0.05^{\mathrm{B}}$ & $0.22 \pm 0.07^{\mathrm{B}}$ & $0.22 \pm 0.07^{\mathrm{B}}$ & $0.45 \pm 0.08^{\mathrm{A}}$ & $0.7 \pm 0.12^{\mathrm{A}}$ & $0.67 \pm 0.13^{\mathrm{A}}$ & $0.12 \pm 0.03^{\mathrm{A}}$ & $0.2 \pm 0.03^{\mathrm{A}}$ & $0.19 \pm 0.04^{\mathrm{A}}$ \\
\hline
\end{tabular}

Values reflect the average for three birds. Values within a column followed by the same superscript letter are not significantly different $(\mathrm{P}<0.05)$

Birds in Group 3, which received the $10^{4.5}$ TCID50/bird dose, showed the most extensive bursal lesions as sever lymphoid degeneration with marked lymphoid depletion, while birds in Group 4, which received the $10^{2.5}$ TCID50/bird dose, exhibited the mildest bursal lesions ranged from mild lymphoid depletion and interfollicular connective tissue formation, that lesions were nonsignificantly different from those of non-vaccinated birds. Finally, birds in group 2 exhibited lesions that were milder than those of Group 3 but more severe than those of group 4. Regenerated lymphoid follicles were observed and increased in number with time passed after vaccination. A marked reduction of the bursal lesions and lesion scores in vaccinated birds was observed with increasing age (Table 3 and Figure 1).

Despite the histopathological changes and the lower relative bursal weight in vaccinated birds, there was no significant difference in the immune response toward AI among any of the four groups. Meanwhile, group 4 showed non-significant difference in ND antibody response, in comparison to group 1, whereas group 2and 3 significant reduction in ND antibody response (Table 4).

Table 3 Severity of vaccination-induced bursal lesions over time, according to the experimental group (mean $\pm \mathrm{SD}$ ).

\begin{tabular}{|c|c|c|c|c|}
\hline Group & $\begin{array}{l}\text { Dose } \\
\text { (TCID }{ }_{50} / \text { bird) }\end{array}$ & $7^{\text {th }}$ day PV & $14^{\text {th }}$ day PV & $21^{\text {st }}$ day PV \\
\hline 1 & none & $0.0 \pm 0.0^{\mathrm{C}}$ & $0.0 \pm 0.0^{\mathrm{C}}$ & $0.0 \pm 0.0^{\mathrm{C}}$ \\
\hline 2 & $10^{3.5}$ & $\begin{array}{l}2.3 \quad \pm \\
0.27^{\mathrm{AB}}\end{array}$ & $2.6 \pm 0.56^{\mathrm{AB}}$ & $1.4 \pm 0.55^{\mathrm{AB}}$ \\
\hline 3 & $10^{4.5}$ & $2.8 \pm 0.27^{\mathrm{A}}$ & $2.3 \pm 0.27^{\mathrm{A}}$ & $2.1 \pm 0.22^{\mathrm{A}}$ \\
\hline 4 & $10^{2.5}$ & $2.3 \pm 0.27^{\mathrm{B}}$ & $2.1 \pm 0.22^{\mathrm{B}}$ & $1.3 \pm 0.67^{\mathrm{B}}$ \\
\hline
\end{tabular}

Values reflect the average for three birds. Values within a column followed by the same superscript letter are not significantly different $(P<0.05)$. PV, post-vaccination

Table 4 Humeral immune response to ND and AI (mean of hemagglutination inhibition $[\mathrm{HI}]$ test units) according to the experimental group.

\begin{tabular}{llll}
\hline Group & Dose (TCID $50 /$ bird $)$ & ND & AI \\
\hline 1 & None & $102.4 \pm 15.6^{\mathrm{A}}$ & $102.4 \pm 15.6^{\mathrm{A}}$ \\
2 & $10^{3.5}$ & $64 \pm 0.0^{\mathrm{B}}$ & $76.8 \pm 12.8^{\mathrm{A}}$ \\
3 & $10^{4.5}$ & $64 \pm 0.0^{\mathrm{B}}$ & $70.4 \pm 15.7^{\mathrm{A}}$ \\
4 & $10^{2.5}$ & $102.4 \pm 15.6^{\mathrm{A}}$ & $83.2 \pm 19.2^{\mathrm{A}}$ \\
\hline
\end{tabular}

Values reflect the average for three birds. Values within a column followed by the same superscript letter are not significantly different $(P<0.05)$. ND: Newcastle disease, AI: avian influenza

\section{DISCUSSION}

The vaccine dose has been suggested to have a significant influence on protective immunity achievement (Islam et al., 2007). Single intra-cloacal IBD virus vaccination with different doses in SPF light-breed chicks induced antibody response with titers reaching up to 8,284 although it induced titer not exceeding 1498 in commercial broiler chicks (Abaza et al., 2020). This discrepancy may reflect differences in the chick's breeds. More potent immune response was induced in SPF light-breed chicks (White Leghorn egg-laying breed) used in this experiment when compared with the commercial heavy-breed chicks. Immune responses in light-breed chicks are predicted to be much more potent than those in heavy-breed chicks (BioCheck, 2017).

In the evaluation of the immune responses across the different groups, a negative correlation was observed between IBD virus antibody titers and vaccine dose (within the used vaccinal dose). This result clarifies the ability of intra-cloacal route to deliver the vaccinal strain to bursae as a tenfold lower dose induced more potent immune response compared with the use of the ordinary and higher doses. The use of low vaccine doses minimizes the costs of vaccines production, thereby improving poultry production profitability.

Vaccinated birds exhibited decreased relative bursal weight and increased bursal lesions severity when compared with non-vaccinated birds. These findings came in disagreement with the observations of Abaza et al., (2020) who recorded non-significant differences in the relative bursal weight and the severity of bursal lesions between vaccinated and nonvaccinated birds. White Leghorn SPF birds were more susceptible to the destructive effects of IBD than commercial or SPF heavy breeds (Nielsen et al., 1998).

There was a considerable reduction in bursal lesion scores over time, as mentioned in table 3 and appearance of regenerated follicles (Figure 1) from activation of bursal stem cells present in neonatal chicks, according to Withers et al., (2006).

The vaccine strain multiplication in the bursae resulted in variable effect on immune response to other vaccines. There was no significant effect on immune response to AI vaccines across the groups, while differences in vaccine doses resulted in differences in ND vaccine-related antibody responses. Chicks vaccinated with the $10^{2.5}$ TCID50/bird dose showed no significant difference in ND or AI antibody responses in compared to non-vaccinated chicks, which suggests that the $10^{2.5} \mathrm{TCID} 50 /$ bird dose of the IBD vaccine strain has no immunosuppressive effects. On the contrary, chicks vaccinated with ordinary and over vaccine doses (groups 2 and 3) exhibited significant immunosuppression, as evidenced by the decrease in ND antibody response. The difference in immune response observed between the ND and AI vaccines may be attributed to the time interval passing between the administration of these vaccines relative to the IBD vaccines (Ali et al., 2004) as intermediate vaccines cause transient immunosuppression to ND vaccine in SPF chicks (Rautenschlein et al., 2007). A similar response to the ND vaccine in SPF chicks was recorded by (Coletti et al., 2001) after in ovo vaccination with D78, while no immunosuppressive effect was recorded in commercial chicks receiving the same vaccine. Even using a ten-fold increase of the intermediate vaccine, no adverse effects on immune responses to other vaccines were observed in commercial chicks by (Terzic et al., 2006). Also, no immunosuppressive effect toward the ND vaccine was observed by Abaza et al., (2020) after intra-cloacal inoculation of the ordinary dose of the D78 vaccine in commercial chicks. This may be attributed to the difference in genetic backgrounds of the breeds and interference of MDA (Rautenschlein et al., 2007). 


\section{CONCULOSIONS}

Intra cloacal administration of IBD vaccine to even at a tenfold dose higher than the ordinary dose, caused neither morbidity nor mortality, except for mild histopathological lesions in the bursae. This indicates the safety and effectiveness of the intra-cloacal vaccination approach. Interestingly, using a dose ten-fold lower than the ordinary dose appears to induce a more potent immune response with non-significant suppressive effects on other vaccine immune responses.

\section{ACKNOWLEDGMENT}

This work is dedicated to the soul of my great Professor Dr Mohammed El-Shorbagy who was the source of the encouragement and support for me all the time, may Allah Almighty bless him and grant him the paradise.
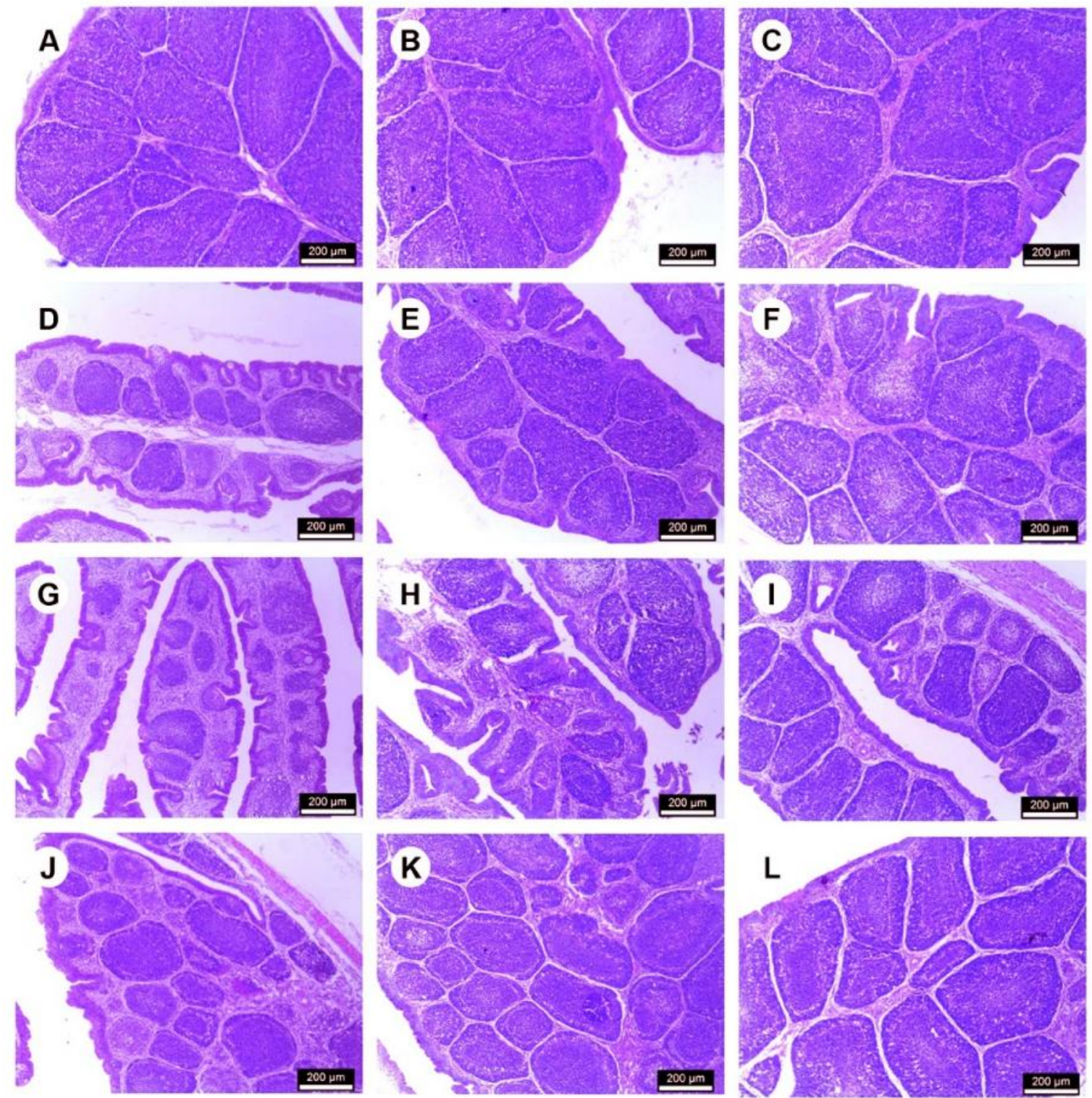

Figure 1 ( $A, B$, and $C$-) Bursae of the negative control group on 7,14 and 21-day post-vaccination respectively showing plicae formed from follicles with darker cortex and less dense medulla under intact mucosal epithelium H\& E X 200. (D-) Bursa of group 2 vaccinated with (10.5 TCID50/ bird) on 7 days post-vaccination showing moderate depletion of lymphocytes with interfollicular connective tissue proliferation $\mathrm{H} \& \mathrm{E}$ X 200 . E and F Bursa of group 2 vaccinated with (10.5 $10^{3.5} \mathrm{TCID} 50 /$ bird) on 14 and 21 day post-vaccination, respectively showing with interfollicular connective tissue proliferation $\mathrm{H} \& \mathrm{EX} 200 . E$ and $\mathrm{F}$ - Bursa of group 2 vaccinated with (10 $0^{3.5}$ TCID50/ bird) on 14 and 21 day post-vaccination, respectively showing regenerated degenerate changes basophilic inflammatory cell infiltration and interfollicular connective tissue proliferation. (I-) Bursa of group 3 vaccinated with (10.5 TCID50/ bird) on 21 days post-vaccination showing small epithelized dith proliferating lymphocytes H\& EX 200 . J- Bursa of group 4 vaccinated with (102.5 TCID50/ bird) on 7 days post-vaccination showing mild lymphoid depletion H\& E X 200. ( $K$-) Bursa of group 4 vaccinated with (10.5 TCID50/ bird) on 14 days post-vaccination
showing regeneration of the follicles with mild interfollicular inflamatory cell infiltration H\& X 200. ( $L$-) Bursa of group 4 vaccinated with (10 $10^{2.5}$ TCID50/ bird) on 21 days postvaccination showing plicae filled with follicles separated by connective tissue trabeculae H\& E X 200

\section{REFERENCES}

1. Abaza, M.A., Elboraay, E.M., Saad, A.E. \& Zayan, K.A. (2020). 
Assessment the role of intracloacal inoculation of live infectious bursal disease vaccine in breaking through maternally derived antibodies. Avian Pathology, 49, 581-588.

2. Ali, A.S., Abdalla, M.O. \& Mohammed, M.E.H. (2004). Interaction between newcastle disease and infectious bursal disease vaccines commonly used in Sudan. International Journal of Poultry Science, 3, 300-304.

3. Banchroft, J.D., Stevens, A. \& Turner, D.R. (1996). Theory and practice of histological techniques. Pathology (Fourth Ed., Vol. 24). New York, London, San Francisco, Tokyo.: Churchil Livingstone.

4. Belyakov, I.M. \& Ahlers, J.D. (2009). What Role Does the Route of Immunization Play in the Generation of Protective Immunity against Mucosal Pathogens? The Journal of Immunology, 183, 6883-6892.

5. BioCheck. (2017). Interpretation and Application of Results Manual. Retrieved from https://www.biochek.com/wpcontent/uploads/2018/01/BIOCHEK-INTERPRETATIONManual.pdf

6. Coletti, M., Rossi, E. Del, Franciosini, M.P., Passamonti, F., Tacconi, G. \& Marini, C. (2001). Efficacy and safety of an infectious bursal disease virus intermediate vaccine in ovo. Avian Diseases, 45, 1036-1043.

7. de Azevedo, R.B. \& Betti, F. (1993). Increase of the bursal follicular medullary compartment in chicks intracloacally inoculated with Bordetella pertussis. Tissue and Cell, 25, 517525 .

8. Eterradossi, N. \& Saif, Y.M. (2019). Infectious Bursal Disease. Diseases of Poultry (14th ed., pp. 257-283). John Wiley \& Sons, Ltd. Retrieved from https://onlinelibrary.wiley.com/doi/ abs/10.1002/9781119371199.ch7

9. Hessell, A.J., Poignard, P., Hunter, M., Hangartner, L., Tehrani, D.M., Bleeker, W.K., Parren, P.W.H.I., Marx, P.A. \& Burton, D.R. (2009). Effective, low-titer antibody protection against lowdose repeated mucosal SHIVchallenge in macaques. Nature Medicine, 15, 951-954.

10. Islam, A.F.M.F., Walkden-Brown, S.W., Groves, P.J. \& Underwood, G.J. (2007). Effects of vaccine dose, virus challenge dose and interval from vaccination to challenge on protection of broiler chickens against Marek's disease virus challenge. Australian Veterinary Journal, 85, 348-355.

11. Nielsen, O.L., Sørensen, P., Hedemand, J.E., Laursen, S.B. \& Jørgensen, P.H. (1998). Inflammatory response of different chicken lines and B haplotypes to infection with infectious bursal disease virus. Avian Pathology, 27, 181-189.

12. Oláh, I., Nagy, N. \& Vervelde, L. (2013). Structure of the Avian Lymphoid System. Avian Immunology: Second Edition (pp. 1144). Elsevier. Retrieved from http://linkinghub.elsevier.com/ retrieve/pii/B9780123969651000029

13. Rautenschlein, S., Kraemer, C., Montiel, E., Vanmarcke, J. \&
Haase, C. (2007). Bilateral Effects of Vaccination Against Infectious Bursal Disease and Newcastle Disease in SpecificPathogen-Free Layers and Commercial Broiler Chickens. Avian diseases, 51, 14-20.

14. Savic, G., Curic, S. \& Savic, V. (2004). Safety Evaluation of Gumbokal ® Im Forte Spf Live Intermediate Vaccine Against Infectious Bursal Disease. Praxis Veterinaria, 52, 135-140.

15. Schlink, G.T. \& Olson, L.D. (1987). Fowl cholera vaccination of growing turkeys with CU strain via routes other than oral. Avian diseases, 31, 22-28. United States.

16. Sharma, J.M., Dohms, J.E. \& Metz, A.L. (1989). Comparative Pathogenesis of Serotype 1 and Variant Serotype 1 Isolates of Infectious Bursal Disease Virus and Their Effect on Humoral and Cellular Immune Competence of Specific-Pathogen-Free Chickens. Avian Diseases, 33, 112.

17. Sorvari, R., Naukkarinen, A. \& Sorvari, T.E. (1977). Anal sucking-like movements in the chicken and chick embryo followed by the transportation of environmental material to the bursa of Fabricius, caeca and caecal tonsils. Poultry science, 56, 1426-1429.

18. Tanimura, N., Tsukamoto, K., Nakamura, K., Narita, M. \& Maeda, M. (1995). Association between pathogenicity of infectious bursal disease virus and viral antigen distribution detected by immunohistochemistry. Avian diseases, 39, 9-20.

19. Terzic, K., Cajavec, S., Kracun, F. \& Savic, V. (2006) Simultaneous vaccination of broilers with live vaccines against infectious bursal disease, Newcastle disease and coccidiosis. Zivinarstvo (Serbia and Montenegro), 41, 5,17-28

20. Teshome, M., Fentahunand, T. \& Admassu, B. (2015). Infectious bursal disease (Gumboro disease) in chickens. British Journal of Poultry Sciences, 4, 22-28.

21. Uenaka, T., Kishimoto, I., Uemura, T., Ito, T., Umemura, T. \& Otsuki, K. (1998). Cloacal Inoculation with the Connecticut Strain of Avian Infectious Bronchitis Virus: An Attempt to Produce Nephropathogenic Virus by in vivo Passage Using Cloacal Inoculation. Journal of Veterinary Medical Science, 60, 495-502.

22. van der Sluis, H.J., Dwars, R.M., Vernooij, J.C.M. \& Landman, W.J.M. (2009). Cloacal reflexes and uptake of fluoresceinlabeled polystyrene beads in broiler chickens. Poultry Science, 88, 1242-1249. Poultry Science Association, Inc. Retrieved from http://dx.doi.org/10.3382/ps.2008-00155

23. Withers, D.R., Davison, T.F. \& Young, J.R. (2006). Diversified bursal medullary B cells survive and expand independently after depletion following neonatal infectious bursal disease virus infection. Immunology, 117, 558-565.

24. World Organization for Animal Health (OIE). (2012). World organization for animal health manual of diagnostic tests and vaccines (mammals, birds and bees) Seventh Edition (Vol. 1). 